\title{
The pool concept in food iron absorption and some of its implications
}

\author{
By Leif Hallberg, Department of Medicine II, University of Göteborg, Sahlgren's \\ Hospital, Göteborg, Sweden
}

The absorption of iron from foods has been extensively studied for many years. It is known that there are at least two kinds of $\mathrm{Fe}$ in the diet with respect to the mechanism of absorption: haem Fe and non-haem Fe. Haem Fe is taken up by the mucosal cells as a porphyrin-Fe complex which is broken down in these cells before $\mathrm{Fe}$ is absorbed ('Turnbull, Cleton \& Finch, 1962; Hallberg \& Sölvell, 1967). It is not known if all non-haem $\mathrm{Fe}$ compounds in the diet are absorbed in a uniform way, even if it is generally assumed that they are absorbed in the same way as $\mathrm{Fe}$ salts.

Studies on foods labelled biosynthetically with radioactive Fe have shown that the absorption may differ markedly from one food to another (see Moore, I968). These differences in availability have been related to differences in solubility and dissociation of the mainly unknown $\mathrm{Fe}$ compounds in foods.

Despite all the information available about $\mathrm{Fe}$ absorption from single foods, little is known about $\mathrm{Fe}$ absorption from the whole diet. The reason is that no simple and accurate method has been available. A meal may contain a number of known and unknown compounds or food items which favour or inhibit Fe absorption (e.g. ascorbic acid, phytates, eggs, meat). A valid estimate of the absorption from a composite meal (based on absorption figures for single foods contained in a meal) is therefore impossible to make. Direct measurements of Fe absorption from the whole diet are thus needed. The chemical balance technique is the only direct method which, theoretically, correctly measures Fe absorption from the whole diet. The method, however, is insensitive, imprecise and laborious. A few careful studies have nonetheless given valuable information about the degree of absorption from a few diets (see Moore, I 968 ).

In many studies, an inorganic radioactive $\mathrm{Fe}$ tracer has been taken as a drink together with various 'standard meals', usually to get an index of absorption in different groups of individuals (normal subjects, subjects with $\mathrm{Fe}$ deficiency, achlorhydria etc.). The absorption of the tracer will not correctly measure the total dietary Fe absorption: it will not measure haem-Fe absorption and it will overestimate the non-haem food $\mathrm{Fe}$ absorption owing to an incomplete isotopic exchange with the native $\mathrm{Fe}$ (Cook, Layrisse, Martinez-Torres, Walker, Monsen \& Finch, 1972; Hallberg \& Björn-Rasmussen, 1972).

There is a need to establish the role of the diet in explaining the high prevalence of $\mathrm{Fe}$ deficiency in many developing countries. The $\mathrm{Fe}$ intake is usually high and there is often no increased loss of Fe. The methodological difficulties in measuring 
Fe absorption from the whole diet in different populations seemed to be unsurmountable. Chemical balance studies were unsatisfactory for reasons already mentioned, and the magnitude of errors was unknown when using an extrinsic inorganic tag as a tracer of the dietary Fe. A WHO-IAEA expert group in 1969 therefore recommended that further studies should be made of the systematic errors involved when using the extrinsic tag as an index of absorption of dietary $\mathrm{Fe}$ in order to get further insight into the aetiology of Fe deficiency and to find effective and realistic ways for its prevention.

\section{Isotopic exchange between non-haem $\mathrm{Fe}$ in foods and an inorganic Fe tracer}

Studies on different foods. At the WHO-IAEA meeting in 1969 it was reported by Dr C. A. Finch that when maize labelled biosynthetically with radioactive Fe was given together with a trace amount of an Fe salt labelled with another radioisotope of $\mathrm{Fe}$, about $40 \%$ more $\mathrm{Fe}$ was absorbed from the extrinsic inorganic tracer than from the maize intrinsic tracer. One explanation for this might be that some $\mathrm{Fe}$ in maize was not available for absorption. Another possibility could be that the condition for isotopic exchange between the extrinsic and intrinsic tracers was not optimal when the extrinsic tracer was given as a drink. We therefore repeated this study, but carefully mixed the extrinsic tracer in the dough before baking maize tortillas. Identical absorption of the two tracers was then found. When the extrinsic tracer was given as a drink we noted the same disagreement in absorption of the two tracers as was reported by Finch. In 1970, at a second WHO-IAEA meeting, we reported our finding that identical absorption of the extrinsic inorganic tracer and intrinsic tracers was seen for maize as well as for soya beans, wheat and eggs in both normal and Fe-deficient subjects. Working from these unexpected observations, we then introduced the concept of a common non-haem $F e$ pool from which the absorption of all non-haem Fe took place. A model for measurement of the absorption of both haem and non-haem iron in the diet was also presented at this meeting (Hallberg \& Björn-Rasmussen, 1972).

A good agreement in absorption of the intrinsic and extrinsic tracers has also been reported by others participating in the cooperative methodological studies initiated at the first WHO-IAEA meeting (Layrisse \& Martinez-Torres, 1972; Sayers, Lynch, Jacobs, Charlton, Bothwell, Walker \& Mayet, r973).

In our further studies comparing the absorption of the intrinsic and extrinsic tracers, a good agreement was seen for a number of foods (Björn-Rasmussen, Hallberg \& Walker, 1972, 1973). The only exception was unmilled, unpolished rice, and it is probable that the outer, dense aleurone layer of the rice grain markedly impairs the diffusion of $\mathrm{Fe}$. Our findings are given in Table $\mathrm{I}$.

Validation studies. A number of studies have been made to compare the absorption of the intrinsic and extrinsic tracers under different conditions. The two tracers were absorbed to the same extent even when inorganic $\mathrm{Fe}$ in various amounts, ascorbic acid or desferrioxamine were added to the diet (Björn-Rasmussen, 1972; Cook et al. 1972; Layrisse, Martinez-Torres, Cook, Walker \& Finch, 1973). 
Table 1. Studies on isotopic exchange between non-haem iron (intrinsic tracer) and an inorganic $\mathrm{Fe}$ salt (extrinsic tracer) in different foods

(Mean values with their standard errors)

\begin{tabular}{|c|c|c|c|c|}
\hline \multicolumn{5}{|c|}{ (Mean values with their standard errors) } \\
\hline \multirow[b]{2}{*}{ Food prepared as or served to: } & \multirow[b]{2}{*}{$\begin{array}{l}\text { No. of } \\
\text { expts }\end{array}$} & \multicolumn{2}{|c|}{ Absorption (\%) } & \multirow{2}{*}{$\begin{array}{l}\text { Mean } \\
\text { absorption } \\
\text { ratio, } \\
\text { extrinsic: } \\
\text { intrinsic }\end{array}$} \\
\hline & & $\begin{array}{c}\text { Intrinsic } \\
\text { tracer }\end{array}$ & $\begin{array}{l}\text { Extrinsic } \\
\text { tracer }\end{array}$ & \\
\hline \multicolumn{5}{|l|}{ Maize } \\
\hline Chapattis & I I & $x \cdot 8 \pm 0.4$ & $r \cdot 7 \pm 0 \cdot 3$ & $0.98 \pm 0.04$ \\
\hline Porridge with ascorbic acid & 6 & $16 \cdot 0 \pm 3.8$ & $17 \cdot 0 \pm 4 \cdot 1$ & $1.06 \pm 0.01$ \\
\hline \multicolumn{5}{|l|}{ Wheat } \\
\hline White bread without Fe supplementation & 5 & $29 \cdot 3 \pm 5 \cdot 6$ & $27 \cdot 2 \pm 5 \cdot 0$ & $0.93 \pm 0.02$ \\
\hline White bread with added ferrous sulphate & 5 & $12.8 \pm 3.7$ & $12 \cdot 6 \pm 3 \cdot 7$ & $0.98 \pm 0.03$ \\
\hline White bread with added desferrioxamine & 6 & $\mathrm{I} \cdot 1 \pm 0 \cdot 2$ & $0.5 \pm 0.2 *$ & $0.40 \pm 0.08$ \\
\hline Brown bread without $\mathrm{Fe}$ supplementation & 5 & $2 \cdot 8 \pm 0.5$ & $3 \cdot 0 \pm 0.7$ & $I .0 I \pm 0.04$ \\
\hline Brown bread with added ferrous sulphate & 4 & $3 \cdot 7 \pm 1 \cdot 6$ & $3.8 \pm 1.4$ & $I \cdot I 3 \pm 0.08$ \\
\hline \multicolumn{5}{|l|}{ Egg } \\
\hline Omelet & 7 & $1.5 \pm 0.5$ & $1.5 \pm 0.5$ & $1 \cdot 03 \pm 0.04$ \\
\hline \multicolumn{5}{|l|}{ Rice } \\
\hline $\begin{array}{l}\text { Porridge prepared from unmilled, unpolished } \\
\text { grains }\end{array}$ & 6 & $2 \cdot 7 \pm r \cdot I$ & $4 \cdot 6 \pm I \cdot 9 *$ & $I \cdot 62 \pm 0.14$ \\
\hline Porridge prepared from milled, polished grains & 6 & $4 \cdot 5 \pm I \cdot I$ & $5 \cdot 2 \pm r \cdot 3 *$ & $x \cdot 17 \pm 0.01$ \\
\hline $\begin{array}{l}\text { Porridge prepared from flour made from milled, } \\
\text { polished grains }\end{array}$ & 6 & $7 \cdot 0 \pm 1 \cdot 4$ & $7 \cdot 0 \pm x \cdot 4$ & $1.0 x \pm 0.02$ \\
\hline \multicolumn{5}{|l|}{ Soya beans } \\
\hline Normal subjects & I5 & $2 \cdot 6 \pm 0.7$ & $2 \cdot 7 \pm 0.7$ & $I \cdot 04 \pm 0.02$ \\
\hline Subjects with achlorhydria & 7 & $0.7 \pm 0.2$ & $0.7 \pm 0.02$ & $1 \cdot 00 \pm 0.01$ \\
\hline Subjects with rapid gastric emptying & 2 & 0.6 & $0 \cdot 6$ & 0.97 \\
\hline Subjects with severe Fe deficiency & 4 & $5 \cdot 7 \pm 1 \cdot 2$ & $5 \cdot 8 \pm I \cdot 2$ & $I .02 \pm 0.02$ \\
\hline
\end{tabular}

Values significantly different from intrinsic tracer: * $P<0.05$.

The two tracers were absorbed to the same extent not only when a doubly labelled food was given alone but also when served together with a composite meal (Cook et al. 1972; Björn-Rasmussen, I973).

The relative radioactivities in plasma of the extrinsic and intrinsic tracers $\left({ }^{5} \mathrm{Fe}\right.$ and ${ }^{59} \mathrm{Fe}$ ) for the first $6-7 \mathrm{~h}$ after serving doubly labelled wheat or soya beans were the same (Fig. I), indicating that an isotopic exchange takes place that is both complete and very rapid (Björn-Rasmussen et al. 1973). The two tracers were also absorbed to the same extent in patients with achlorhydria, rapid gastric emptying or Fe deficiency (Björn-Rasmussen, r973).

The validity of the interpretation that a rapid and complete isotopic exchange occurs was further tested by serving an omelet prepared from eggs and white wheat flour biosynthetically labelled with different radioactive $\mathrm{Fe}$ isotopes. Eggs and wheat were chosen because of the great difference in the absorption of Fe from these foods when given alone (Björn-Rasmussen et al. I973). Almost identical absorptions of the radioactive $\mathrm{Fe}$ isotopes were found.

In summary, there is strong evidence that the absorption of Fe from a radioactive inorganic tracer is the same as from the native non-haem $\mathrm{Fe}$ in a great number of foods forming important natural Fe sources in many diets. It is proposed that the $33(3) 7$ 

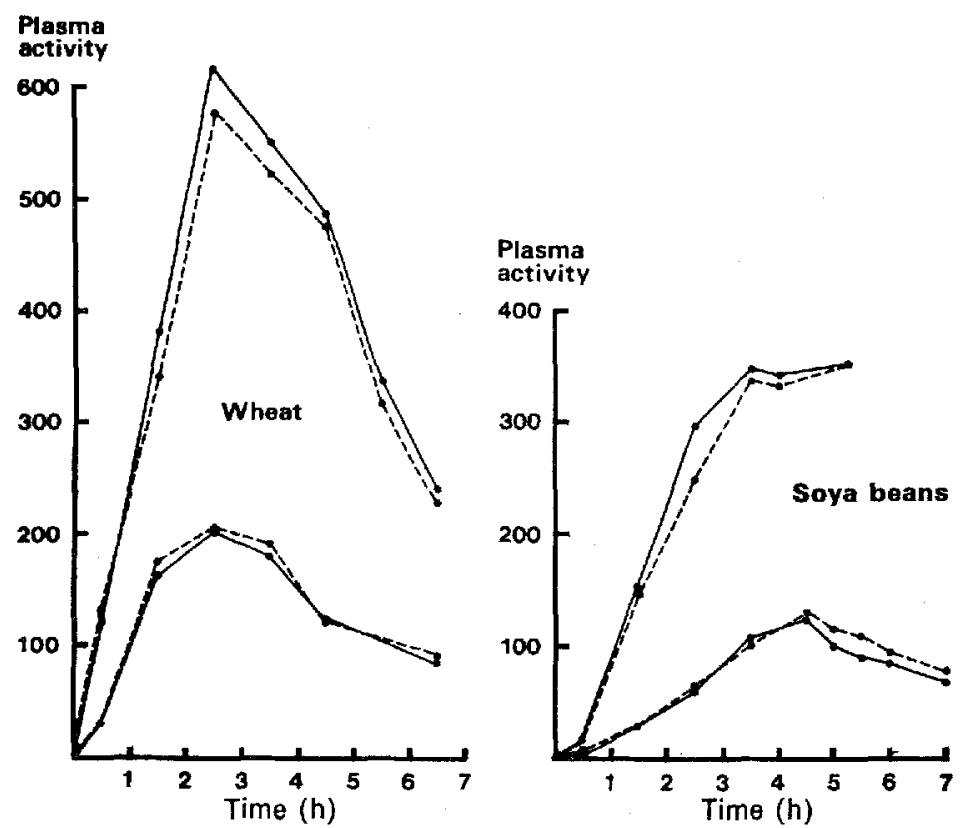

Fig. I. Plasma radioactivity (arbitrary units) of extrinsic and intrinsic tracers after a meal. Two subjects were served a white wheat bread meal and two other subjects a soya-bean meal. 'The meals were prepared from wheat or soya beans biologically labelled with ${ }^{55} \mathrm{Fe}$ (intrinsic tracer) and an added inorganic iron salt labelled with ${ }^{59} \mathrm{Fe}$ (extrinsic tracer). The relative radioactivity of the two tracers appearing in plasma after the meals was then followed (from Björn-Rasmussen, Hallberg \& Walker, 1973).

Extrinsic tracer;

reason for the identical absorption of the extrinsic tracer and the native $\mathrm{Fe}$ is a complete and rapid isotopic exchange within a common pool of non-haem Fe.

\section{The pool concept}

The fact that non-haem $\mathrm{Fe}$ in a great number of foods studied can be uniformly labelled by an extrinsic tracer implies that the non-haem Fe in a composite meal can be uniformly labelled. All non-haem $\mathrm{Fe}$ in a meal can therefore be considered as a unity, a non-haem Fe pool. Some of the non-haem Fe compounds in the diet are probably only partly soluble or partly dissociated, or both. The isotopic exchange between the native $\mathrm{Fe}$ (i.e., the biosynthetically incorporated tracer) and the extrinsic tracer will probably occur in a common 'active' part of the pool (pool of isotopic exchange). The isotopic exchange observed between the intrinsic tracers of eggs and wheat will, of course, also be mediated through such a pool of isotopic exchange. Even if it is not known in what chemical form non-haem $\mathrm{Fe}$ is taken up by the mucosal cells, it is reasonable to assume that the absorption directly or indirectly takes place from this pool of isotopic exchange, which thus also will form a 'pool of absorption' (Fig. 2).

Differences in absorbability (availability) of Fe from single foods may be considered as differences in the relative size of their 'pool of exchange'. The effect of 


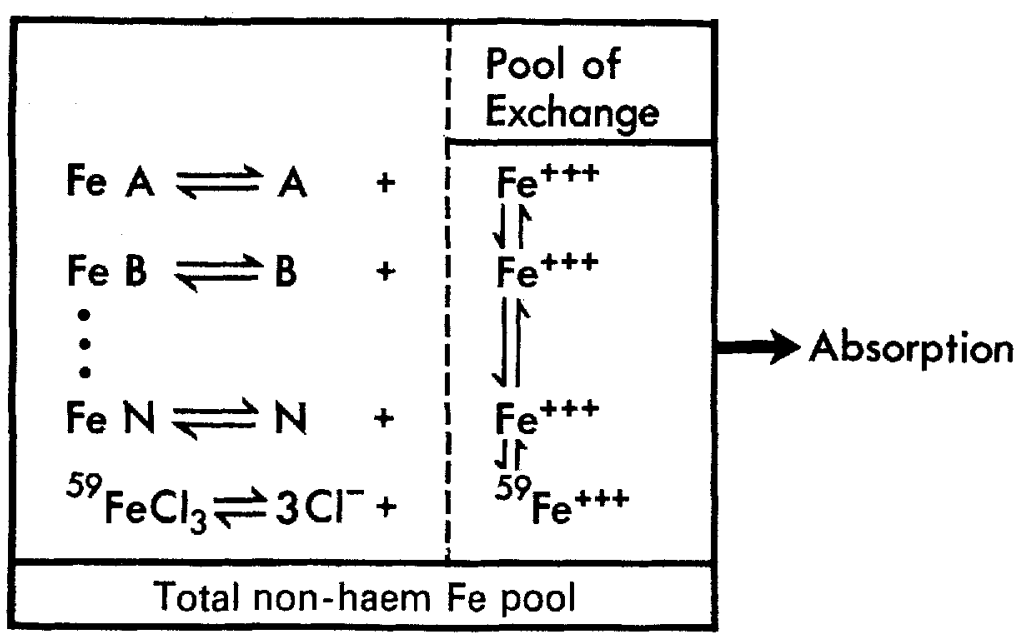

Fig. 2. Model showing hypothetical pool of isotopic exchange of dissolved and dissociated nonhaem iron compounds in a meal and the added inorganic radioactive Fe tracer.

factors known to influence absorption of $\mathrm{Fe}$ from single foods (such as ascorbic acid, meat, eggs and phytates) may be related to their effects on the size of the pool of exchange. Factors reducing the absorption, such as phytates and eggs, may thus reduce the pool of exchange by forming more insoluble or undissociated $\mathrm{Fe}$ compounds.

The pool concept thus implies that the composition of a meal may greatly affect not only the amount of non-haem Fe but also the properties of the pool of isotopic exchange and thus also the absorbability of the $\mathrm{Fe}$ in the meal. The absorption will thus not be a sum of the absorption from the single foods contained in a meal but a net effect of all food items and their constituents comprising both $\mathrm{Fe}$ and non-Fe compounds.

Isotopic exchangeability and availability of food $\mathrm{Fe}$ are thus not identical concepts. Non-haem $\mathrm{Fe}$ in most foods may be completely and rapidly exchangeable with an extrinsic tracer, but some Fe compounds may be very poorly available for absorption (may contribute very little to the pool of isotopic exchange). This fact will not introduce an error in determining the absorption of non-haem Fe provided that the exchangeable $\mathrm{Fe}$ is the same as the $\mathrm{Fe}$ determined chemically (to which the fraction of absorption of radioactive $\mathrm{Fe}$ is related).

\section{Implications of the pool concept}

New methodology. The fact that radioactive Fe-labelled haemoglobin may be used as a good tracer of haem-Fe absorption from the food (Hallberg \& Björn-Rasmussen, 1972; Layrisse \& Martinez-Torres, 1972) and that a radioactive Fe-labelled Fe salt may be used as a tracer of non-haem-Fe absorption implies that both haem and nonhaem-Fe absorption can be determined simultaneously from the same meal using two radioactive $\mathrm{Fe}$ isotopes (Hallberg \& Björn-Rasmussen, 1972). For studies on 
meals comprising only or mainly non-haem $\mathrm{Fe}$, a 'one pool-one radioisotope' model may of course also be applied.

The accuracy of this method was studied in a homogenous group of normal young men considered to be in a steady state with respect to Fe balance. The absorption from the whole diet (the sum of all meals) agreed very well with the estimated daily need for Fe to cover losses (Björn-Rasmussen, Hallberg, Isaksson $\&$ Arvidsson, I974). The reproducibility of the measurements of non-haem-Fe absorption using the present method is good, the over-all error being $8 \%$ (Hallberg, Garby, Suwanik \& Björn-Rasmussen, I 974). In all these studies the radioactive Fe has been mixed into a meal which was carefully minced and mixed before serving. Recent studies indicate that accurate measurements of Fe absorption from a composite meal can be obtained when the isotope is mixed into only one of the bulky components of the food. There is therefore good reason to believe that a realistic and convenient 'field method' may be designed which allows measurements of $\mathrm{Fe}$ absorption from typical diets in different populations.

The new methodology for measurement of food Fe absorption has greatly facilitated studies on Fe absorption from meals of different composition in different groups of subjects (Hallberg et al. 1974; Layrisse, Martinez-Torrcs \& González, I974). The new technique has also made it possible to study a great variety of factors that may influence the absorption of non-haem Fe (Björn-Rasmussen, 1974; Björn-Rasmussen \& Hallberg, 1974).

Various experimental models may be used, comparing, for instance, two kinds of meals labelled with different $\mathrm{Fe}$ isotopes in the same subjects, or comparing the ability of different subjects to absorb $\mathrm{Fe}$ in a meal by using one $\mathrm{Fe}$ isotope to label the meal and another isotope to label an Fe salt given at another time (on alternate days) as a reference for the ability of the single individual to absorb Fe.

Alternative ways to improve Fe nutrition. The pool concept implied that the absorption of non-haem Fe from a meal is related not only to the amount of nonhaem $\mathrm{Fe}$ in the meal but also to the properties (size) of the 'pool of isotopic exchange'. An excess of phytates may thus be expected to decrease the absorption of all nonhaem $\mathrm{Fe}$, which also may be achieved by including an egg in a meal. Ascorbic acid or meat will increase the absorption of all non-haem $\mathrm{Fe}$ compounds.

An increased absorption of non-haem Fe from a meal may thus be achieved in several different ways: ( $\mathrm{I}$ ) by increasing the Fe content of the diet e.g. by enrichment; (2) by increasing the content of foods or compounds that enhance the absorption of non-haem Fe (e.g. ascorbic acid, meat); (3) by reducing the content of compounds or foods inhibiting absorption (e.g. phytates, eggs).

This way of looking at food $\mathrm{Fe}$ absorption is probably especially important in many developing countries, as the diet in many of these countries seems to contain an excess of compounds that inhibit Fe absorption (Hallberg et al. 1974). Such compounds in excess may thus make fortification programmes less effective because they will, to the same extent, interfere with the added Fe. Alternative ways to improve Fe nutrition need therefore to be considered. Extensive studies on maize have shown that it may contain a great excess of an inhibitor for $\mathrm{Fe}$ absorption which 
thus makes it more difficult to fortify diets containing maize (Layrisse et al. 1973).

The level of fortification with $\mathrm{Fe}$ needed to achieve a desired improvement in $\mathrm{Fe}$ nutrition is thus related to the properties of the diet which is to be fortified and to the properties of the Fe compound used. It is therefore necessary that, before starting fortification programmes on a broader scale, absorption studies on typical composite meals are made to ensure that the fortification is adequate.

\section{REFERENCES}

Björn-Rasmussen, E. (1972). Scand. F. Haemat. 1x, 39 r.

Björn-Rasmussen, E. (I973). Scand. F. Gastroent. 8, 645.

Björn-Rasmussen, E. (1974). Nutr. Metab. 16, I01.

Björn-Rasmussen, E. \& Hallberg, L. (1974). Nutr. Metab. r6, 94.

Björn-Rasmussen, E., Hallberg, L., Isaksson, B. \& Arvidsson, B. (I974). F. clin. Invest. 53, 247.

Björn-Rasmussen, E., Hallberg, L. \& Walker, R. B. (1972). Am. F. clin. Nutr. 25, 3 I7.

Björn-Rasmussen, E., Hallberg, L. \& Walker, R. B. (1973). Am. F. clin. Nutr. 26, I3I1.

Cook, J. D., Layrisse, M., Martinez-Torres, C., Walker, R., Monsen, E. \& Finch, C. A. (1972). F. clin. Invest. 51, 805 .

Hallberg, L. \& Björn-Rasmussen, E. (1972). Scand. J. Haemat. 9, 193.

Hallberg, L., Garby, L., Suwanik, R. \& Björn-Rasmussen, E. (1974). Am. F. clin. Nutr. 27, 826.

Hallberg, L. \& Sölvell, L. (1967). Acta med. scand. r8x, 335.

Layrisse, M. \& Martinez-Torres, C. (1972). Am. F. clin. Nutr. 25, $40 \mathrm{I}$.

Layrisse, M., Martinez-Torres, C., Cook, J. D., Walker, R. \& Finch, C. A. (I973). Blood 4I, 333.

Layrisse, M., Martinez-Torres, C. \& González, M. (1974). Am. J. clin. Nutr. 27, 152.

Moore, C. V. (I968). In Occurrence, Causes and Prevention of Nutritional Anemias. Symp. vi, Swedish Nutrition Foundation p. 92 [G. Blix, editor]. Uppsala: Almquist \& Wiksell.

Sayers, M. H., Lynch, S. R., Jacobs, P., Charlton, R. W., Bothwell, T. H., Walker, R. B. \& Mayet, F. (1973). Br. . Haemat. 24, 209.

Turnbull, A., Cleton, F. \& Finch, C. A. (1962). F. clin. Invest. 41, 1897. 